\title{
Epizootiology of the ectoparasitic protozoans Ichthyobodo salmonis and Trichodina truttae on wild chum salmon Oncorhynchus keta
}

\author{
Shinya Mizuno ${ }^{1, *}$, Shigehiko Urawa ${ }^{2}$, Mahito Miyamoto ${ }^{1}$, Hayato Saneyoshi ${ }^{1}$, \\ Makoto Hatakeyama ${ }^{1}$, Nobuhisa Koide ${ }^{1}$, Hiroshi Ueda ${ }^{3}$

\footnotetext{
${ }^{1}$ Salmon and Freshwater Fisheries Research Institute, Hokkaido Research Organization, Eniwa, Hokkaido 061-1433, Japan

${ }^{2}$ Hokkaido National Fisheries Research Institute, Japan Fisheries Research and Education Agency, Sapporo 062-0922, Japan ${ }^{3}$ Field Science Center for Northern Biosphere, Graduate School of Environmental Science, Hokkaido University, Sapporo,
} \\ Hokkaido 060-0809, Japan
}

\begin{abstract}
Infestations of the ectoparasitic flagellate Ichthyobodo salmonis and the ciliate Trichodina truttae have caused acute mortalities of hatchery-reared juvenile chum salmon Oncorhynchus keta in Hokkaido, northern Japan. This study examined the epizootiology of I. salmonis and T. truttae on wild chum salmon as a possible infection source of the 2 parasitic protozoans in hatcheries. Infestations by both ectoparasites were detected on freshwater-adapted adult and juvenile chum salmon in all 4 rivers examined. This is the first study of an anadromous Pacific salmonid to report infestation of $I$. salmonis and T. truttae in adults returning for spawning. Among the marine-inhabiting phase of chum salmon, infestation with I. salmonis, but not T. truttae, was observed on adults and juveniles. The 2 protozoans were experimentally transmitted at the same time from wild to hatchery-reared chum salmon juveniles, and caused a high rate of mortality in the hatchery fish. In freshwater, the proliferation rate of $T$. truttae was greater than that of $I$. salmonis. These observations show that the euryhaline ectoparasite I. salmonis can infest chum salmon throughout their life cycle, in both river and ocean habitats, whereas T. truttae is able to infest these salmonids only in freshwater. Furthermore, wild chum salmon were shown to be a potential infestation source for both T. truttae and I. salmonis in hatchery fish.
\end{abstract}

KEY WORDS: Hatchery fish $\cdot$ Ichthyobodosis $\cdot$ Infestation experiment $\cdot$ Pacific salmon $\cdot$ Trichodinosis

\section{INTRODUCTION}

Hatchery programs for chum salmon Oncorhynchus keta stock enhancement using artificial propagation are widely developed in Hokkaido, northern Japan (Kobayashi 1980). However, ectoparasitic protozoan infestations of juvenile chum salmon can cause serious levels of mortality among fish cultured in freshwater hatcheries. The flagellate Ichthyobodo salmonis and the ciliate Trichodina truttae frequently parasitize the body surface and/or gills of juvenile salmon (Urawa 1992a,b, Mizuno et al. 2017). The percentage of hatcheries in Hokkaido positive for these parasites was $26-35 \%$ for I. salmonis (Urawa 1992c,
Mizuno et al. 2017) and 15-32\% for T. truttae (Urawa 1992C, Mizuno et al. 2016). Infestation experiments have demonstrated that $I$. salmonis disturbs the osmoregulation of juvenile chum salmon owing to skin destruction, consequently reducing the marine survival of the anadromous host (Urawa 1993). Heavy T. truttae infestations cause extreme flashing (abnormal swimming motion in which fish suddenly and briefly turn onto their sides) among afflicted fish, followed by mass host mortalities, with a cumulative loss of up to $56 \%$ in freshwater stocks (Urawa 1992b).

Bathing juveniles in diluted corn vinegar (Urawa 2013) or seawater (Khan 1991) can control infestations of I. salmonis or T. truttae, respectively. How- 
ever, to interrupt the infestation route as a preventive measure, it is essential to identify the infestation sources of I. salmonis and T. truttae. In Hokkaido, T. truttae infests a variety of wild salmonids, including adult chum salmon, masu salmon $O$. masou, rainbow trout $O$. mykiss, white-spotted char Salvelinus leucomaenis, and dolly varden S. malma. Moreover, hatchery-reared chum salmon juveniles have been experimentally infested with $T$. truttae from wild masu salmon (Mizuno et al. 2016). In comparison, I. salmonis can infest chum salmon, but apparently not masu salmon, from which Ichthyobodo parasites have been isolated and described as a new species (Urawa et al. 2014). Additionally, the source of I. salmonis in hatcheries remains unclear since infestations have occurred in ponds supplied with unsterilized spring or well water, in which residual wild fish were absent (Urawa 1992c). In northern Japan, adult chum salmon migrate upstream for spawning from September to January, while juveniles migrate from the river to the sea from March to May (Salo 1991). Adults used for artificial fertilization are stocked in hatchery ponds until ovulation or spermiation, from September to December, and the fertilized eggs, hatched larvae, fry, and juveniles are cultured in hatcheries from September until the next May (Kobayashi 1980). Therefore, either or both adult and juvenile wild chum salmon may be possible infestation sources of $I$. salmonis and T. truttae in hatcheryreared juveniles, such as via the transfer of wild stocks or untreated river water to hatcheries. However, researchers have yet to describe the actual infestation status among wild chum salmon at various developmental stages or the route of transmission from wild chum salmon to hatchery-reared juveniles.

Here we examined the status of infestation with I. salmonis and/or T. truttae among adult chum salmon in Hokkaido during their spawning migration from the ocean to their natal river, and among juveniles during their downstream migration. Furthermore, experimental transmission of $I$. salmonis and T. truttae from wild juveniles to hatchery-reared juveniles was performed to further ascertain potential infection sources of these 2 ectoparasites.

\section{MATERIALS AND METHODS}

\section{Fish}

Wild chum salmon Oncorhynchus keta adults (approximately $2.0-4.0 \mathrm{~kg}$ body weight) on their spawn- ing migration, and juveniles (approximately 0.5-1.2 g) on their downstream migration in Hokkaido were captured from rivers and in the sea, between October 2013 and November 2015. Adult fish were caught using set nets, cast nets, or scoop nets, whereas juveniles were captured with cast nets only. Table 1 lists the sampling times, growth stages, rivers/locations, latitude/longitude of the sampling points, water temperature and salinity, sex and number of fish, and the host body samples collected. The 4 rivers where the salmon were collected were designated by the letters A to $\mathrm{D}$ in conjunction with information on the latitude/ longitude of the various sampling points. Adults were collected from Rivers A, B, C, and D as well as from the river mouth and offshore regions of River $D$, whereas juveniles were collected in Rivers A and B and at a fishery port near the mouth of River A (Table 1). The instream-living juveniles collected for the study were regarded as wild fish because they inhabited streams where hatchery-reared juveniles are not released. In the past, hatcheries that utilized untreated water from Rivers A, B, C, and D for the culture of juvenile chum salmon experienced Trichodina truttae and/or Ichthyobodo salmonis infestations of the hatchery-reared fish (Urawa 1992c, Mizuno et al. 2016, 2017). Of 60 wild chum salmon juveniles collected from River A on 13 May 2014, 50 were maintained live and used as potential infestation sources in a transmission experiment. To supply non-infested fish for that experiment, a total of 1220 chum salmon were cultured at the Salmon and Freshwater Fisheries Research Institute in Hokkaido, from mid-November 2013 until 13 May 2014, without allowing them to become infested by $T$. truttae or $I$. salmonis. Other adults and juveniles were used for analyses of the infestation status of $T$. truttae and $I$. salmonis in wild chum salmon.

\section{Collection of T. truttae and I. salmonis from host body surfaces}

The fins of individual adult chum salmon (i.e. pectoral, dorsal, adipose, pelvic, anal, and caudal, $\mathrm{n}=5$ or 10 fish) were excised using anatomical scissors and then pooled as a single sample. To detach the ectoparasitic protozoans from the skin (Callahan \& Noga 2002), each individual sample was placed in a $50 \mathrm{ml}$ polypropylene conical tube and then completely bathed in $20 \mathrm{ml}$ of $1 \mathrm{~g} \mathrm{l}^{-1}$ unbuffered tricaine methanesulfonate (MS-222; Sigma-Aldrich). Juvenile chum salmon $(\mathrm{n}=10)$ were preserved individually in $6.0 \mathrm{ml}$ of the MS-222 solution contained in a $15 \mathrm{ml}$ 


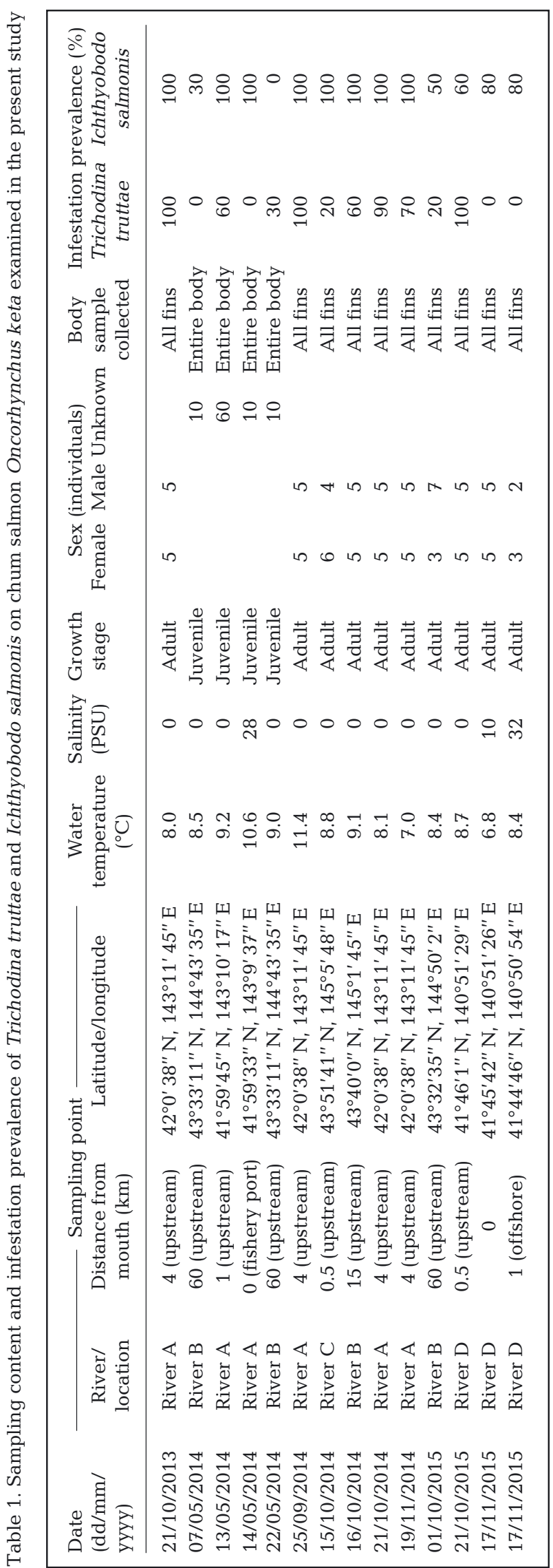

polypropylene conical tube. After incubation at $4{ }^{\circ} \mathrm{C}$ for $10 \mathrm{~min}$, the fin samples of the adults and the bodies of juveniles were removed from the tubes using sterilized forceps and their wet weights were measured separately. The surfaces of the fins from adults and whole juvenile bodies were individually observed at a magnification of $1.0 \times 10^{3}$ using a low vacuum type microscope (Miniscope TM3030 Plus, Hitachi) to confirm no residual ectoparasitic protozoans.

\section{Quantification of the two protozoans on the host body surfaces}

T. truttae on the body surfaces were counted directly, following the method of Mizuno et al. (2016). The total number of $T$. truttae released into the MS222 solution of each sample tube was counted under a stereomicroscope after using a micropipette to place all of the solution from the tube onto a macroplankton counting plate (Model 5608-F; RIGO). The counted trichodinid ciliates were identified as T. truttae based on morphology, as described by Urawa \& Arthur (1991). Infestation intensity of T. truttae was given as number of $T$. truttae $\mathrm{g}^{-1}$ wet sample weight (ind. $\mathrm{gSW}^{-1}$ ). After counting the T. truttae, the volume of MS-222 solution was returned to the original polypropylene conical tube by pipetting and then centrifuged at $2.9 \times 10^{4} \mathrm{~m} \mathrm{~s}^{-2}$ for $5 \mathrm{~min}$ at $4^{\circ} \mathrm{C}$.

Slight infestations of $I$. salmonis $(\sim 10 \mu \mathrm{m}$ in size $)$ on the body surfaces of chum salmon are very difficult to detect with light microscopic observation. In extremely heavy infections, it is also difficult to count total numbers of $I$. salmonis. Accordingly, $I$. salmonis were indirectly quantified using the copy number of the absolute small-subunit ribosomal RNA gene (rDNA), which was expressed as the absolute number of $I$. salmonis parasites using linear regression and analyzed by real-time quantitative polymerase chain reaction (qPCR) (Mizuno et al. 2017). Next, the supernatant was completely removed by pipetting, and the precipitate was used to quantify I. salmonis. Nucleic acids consisting of total DNA and a portion of the RNA were extracted from the precipitate samples using a nucleic acid purification and extraction kit (SepaGene; Eidia) and dissolved in $20 \mu \mathrm{l}$ Tris-EDTA buffer solution $(10 \mathrm{mmol}$ $\mathrm{l}^{-1}$ Tris- $\mathrm{HCl}, 1.0 \mathrm{mmol} \mathrm{l}^{-1}$ EDTA; $\mathrm{pH}$ 8.0). Each aliquot of the reaction mixture (total volume $50 \mu \mathrm{l}$ ) was loaded into a single well of a 96-well microplate containing $25 \mu$ of $2 \times$ PCR mixture (Power SYBR® Green PCR Master Mix; Thermo Fisher Scientific), $0.5 \mu \mathrm{l}$ of $50 \mu \mathrm{mol} \mathrm{l}^{-1}$ forward primer (final concentra- 
tion $0.5 \mu \mathrm{mol} \mathrm{l}^{-1}$ ), $0.5 \mu \mathrm{l}$ of $50 \mu \mathrm{mol} \mathrm{l}^{-1}$ reverse primer

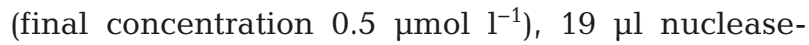
free distilled water, and $5.0 \mu \mathrm{l}$ nucleic acid template. Primers that did not cross-react with Ichthyobodo sp. from masu salmon in Hokkaido (Urawa et al. 2014) were designed to specifically amplify the $276 \mathrm{bp}$ partial rDNA of I. salmonis (Mizuno et al. 2017). The nucleotide sequences of the primers were (forward) 5'-GTC GTT GTT ACC GAT GCC-3' and (reverse) 5'-GCT GTA TCT CCC TTC CCC-3'. The PCRs were conducted using 40 cycles of a real-time qPCR system (QuantStudio ${ }^{\text {TM }} 6$ Flex Real-Time PCR System; Thermo Fisher Scientific) after initial activation at $95^{\circ} \mathrm{C}$ for $10 \mathrm{~min}$; each cycle consisted of denaturation at $95^{\circ} \mathrm{C}$ for $30 \mathrm{~s}$ and then annealing and elongation at $60^{\circ} \mathrm{C}$ for $30 \mathrm{~s}$. The rDNA copy number included in the original sample was calculated from the standard curve and measured sample values. The measured value was regarded as zero if rDNA was undetectable in a sample. Infestation intensity was given as the number of $I$. salmonis rDNA copies $\mathrm{gSW}^{-1}$ and classified according to sampling time and river/location for each of the adults and juveniles; data are presented as means \pm standard deviations. Infestation prevalence was calculated as a percentage of the number of parasite-positive samples / total number of samples, and classified by sampling time and river/location for each of the adults and juveniles.

\section{Transmission experiment}

A transmission experiment was performed at the Salmon and Freshwater Fisheries Research Institute on 13 May 2014. Two groups of 600 hatchery-reared chum salmon juveniles (mean weight $1.2 \mathrm{~g}$ ) that were free of infestation with $T$. truttae or I. salmonis were introduced into $45 \mathrm{l}$ tanks supplied with spring water $\left(8^{\circ} \mathrm{C}\right)$ at a flow rate of $3.61 \mathrm{~min}^{-1}$. A net basket (size: $15 \times 10 \times 15 \mathrm{~cm}$, mesh opening: $2 \times 2 \mathrm{~mm}$ ) was floated in each tank for separating the (potentially) infested fish (which were yet to be added) from the initially non-infested fish. One 451 tank was set as the 'noninfested' control group, while the other was designated the 'infested' group. Fifty juvenile wild chum salmon, captured from River A on 13 May 2014 (Table 1), were accommodated in the tank basket of the 'infested group,' whereas no fish were added to the tank basket of the control group. On Day 7 (20 May), the baskets were removed from the 2 tanks. Thereafter, the 2 groups of juveniles were reared until Day 63 (15 July). A commercial pelleted trout feed was supplied at approximately $2 \%$ body weight $\mathrm{d}^{-1}$ to each group. Mortality was checked daily during the $63 \mathrm{~d}$ experiment, and any dead fish were promptly removed to prevent deterioration of water quality. Ten fish from each group were sampled at $7 \mathrm{~d}$ intervals. The parasite infestation intensity was calculated according to the analysis of infestation status among the wild juveniles, described above. Data on mortality were presented as a weekly cumulative percentage of mortalities at $7 \mathrm{~d}$ intervals.

\section{Statistical analyses}

The infestation intensities of T. truttae and I. salmonis were compared among sampling times or among sampling points on each river for an analysis of infestation status among the wild chum salmon. In the transmission experiment, the infestation intensities were compared between the control and infested groups from each sampling time, as well as the sampling times of each group. Data with no infestation (zero) on wild chum salmon were excluded from statistical datasets. An assessment of the normality of the statistical datasets was performed: if a dataset was not normally distributed, comparisons of infestation intensity among 3 or more groups were done using the Kruskal-Wallis test followed by the Mann-Whitney $U$-test with the Bonferroni correction, whereas comparisons of infestation intensity between only 2 groups were done using the original Mann-Whitney U-test. A p-value of $<0.05$ was considered significant. All statistical analyses were performed using Statcel2 software (OMS Publishing).

\section{RESULTS}

\section{Trichodina truttae infestation prevalence and intensity in wild adults}

T. truttae infested adult salmon at an estimated prevalence of 20-100\% (Table 1), but the protozoan was not detected on fish collected from the river mouth (brackish water) or the offshore area (seawater) of River D. The prevalence in River A in 2014 revealed a decreasing tendency from September $(100 \%)$ to October (90\%) and November (70\%; Table 1). Annual variations in infestation prevalence in October were found when comparing data for River A in 2013 (100\%) and 2014 (90\%), and for River $\mathrm{B}$ in 2014 (60\%) and 2015 (20\%) (Table 1). The infes- 
tation intensity of $T$. truttae ranged from $7.50 \times 10^{-3}$ to 33.2 ind. $\mathrm{gSW}^{-1}$ among the infested salmon in rivers. A dataset composed of 4 data from River A showed a significant difference using Kruskal-Wallis test ( $\mathrm{p}<0.01)$, whereas a dataset constructed of 2 data from River B showed no difference using a MannWhitney $U$-test $(\mathrm{p}=0.204)$. Significant differences detected using a Mann-Whitney $U$-test with the Bonferroni correction showed that October 2013 (11.7 \pm 21.6 ind. gSW $^{-1}$ ) had significantly greater intensity compared to either September (0.569 \pm 0.822 ind. $\left.\mathrm{gSW}^{-1}, \mathrm{p}<0.001\right)$, October $\left(0.507 \pm 1.23\right.$ ind. $\mathrm{gSW}^{-1}$, $\mathrm{p}<0.001)$, or November 2014 (0.340 \pm 1.00 ind. $\mathrm{gSW}^{-1}, \mathrm{p}<0.001$ ) in River A (Fig. 1). On the other hand, there were no differences in the infestation intensity among September, October, and November 2014 in River A (Mann-Whitney $U$-test with Bonferroni correction, $\mathrm{p}>0.05)$.

\section{Ichthyobodo salmonis infestation prevalence and intensity in wild adults}

For all sections of Rivers A, B, C, and D (freshwater), and at the mouth (brackish water) and offshore area (seawater) of River D, the infestation prevalence of I. salmonis on wild chum salmon adults ranged from 50 to $100 \%$ (Table 1). Infestation prevalence on adults

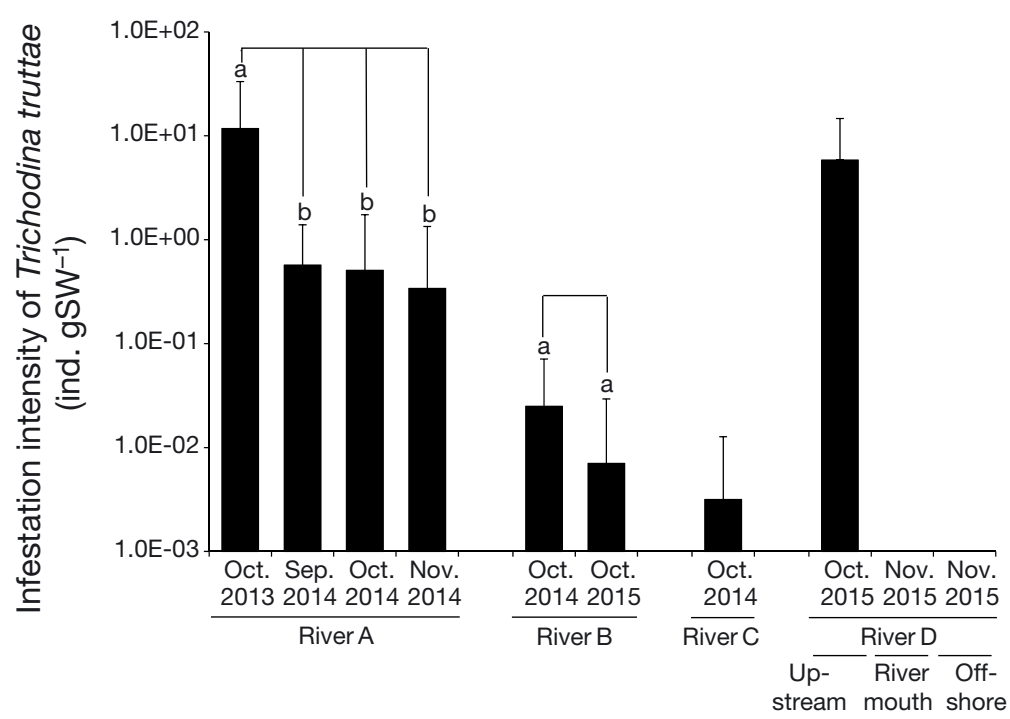

Fig. 1. Infestation intensity of Trichodina truttae in adult wild chum salmon Oncorhynchus keta. Data are expressed as means \pm SD $(n=5-10)$. Data on the mouth and offshore of River D showed no infestation of T. truttae. The infestation intensities of $T$. truttae among sampling times or among sampling points on each river were statistically compared using either a Kruskal-Wallis test followed by a Mann-Whitney $U$-test with Bonferroni correction, or the original Mann-Whitney $U$-test. Different superscripts on the data columns indicate significant differences $(p<0.05)$ collected in the upstream region of River D (60\%) was small compared to adults at the river mouth and offshore $(80 \%$ in both regions; Table 1$)$. No monthly variations in infestation prevalence (all data were $100 \%$ : Table 1) were observed among River A datasets for September, October, and November 2014. Annual variations in prevalence were found between October data for 2014 (100\%) and 2015 (50\%) in River $\mathrm{B}$, but no variation was found between October data for 2013 (100\%) and 2014 (100\%) in River A (Table 1). The infestation intensity of $I$. salmonis ranged from 555 to $3.39 \times 10^{6}$ rDNA copies $\mathrm{gSW}^{-1}$ among the infested adult salmon. A Kruskal-Wallis test showed a significant difference in a dataset composed of 4 data from RiverA $\left(\mathrm{p}=1.04 \times 10^{-3}\right)$ but no difference in a dataset constructed by 3 data from River D ( $\mathrm{p}=$ 0.327). Significant differences observed by the Mann-Whitney $U$-test with the Bonferroni correction showed significantly greater intensity in October $2013\left(1.15 \times 10^{6} \pm 1.49 \times 10^{6}\right.$ rDNA copies $\left.\mathrm{gSW}^{-1}\right)$ compared to either September $\left(1.09 \times 10^{4} \pm 9.55 \times 10^{3}\right.$ rDNA copies $\left.\mathrm{gSW}^{-1}, \mathrm{p}<0.001\right)$, October $\left(1.34 \times 10^{4} \pm\right.$ $1.57 \times 10^{4}$ rDNA copies $\mathrm{gSW}^{-1}, \mathrm{p}<0.001$ ), or November $2014\left(5.34 \times 10^{3} \pm 3.73 \times 10^{3}\right.$ rDNA copies $\mathrm{gSW}^{-1}$, $\mathrm{p}<0.001$ ) in River A (Fig. 2). However, there were no differences in the intensity among September, October, and November 2014 in River A (Mann-Whitney $U$-test with the Bonferroni correction, $\mathrm{p}>0.05)$. In addition, the Mann-Whitney $U$-test revealed significantly higher intensity in October $2014\left(2.61 \times 10^{4} \pm 2.85 \times 10^{4}\right.$ rDNA copies $\mathrm{gSW}^{-1}$ ) compared to October $2015\left(1.71 \times 10^{3} \pm 4.09 \times 10^{3}\right.$ rDNA copies $\left.\mathrm{gSW}^{-1}\right)$ in River $\mathrm{B}(\mathrm{p}<0.001$; Fig. 2).

\section{T. truttae infestation prevalence and intensity in wild juveniles}

In River A, T. truttae infestation prevalence was $100 \%$ among fish collected in upstream regions (freshwater) but $0 \%$ at the river mouth (brackish water; Table 1). In River B, infestation prevalence was $0 \%$ on 7 May 2014 and $30 \%$ on 22 May 2014 (Table 1). The infestation intensity in the upstream region of River A was $1.21 \pm 1.76$ ind. $\mathrm{gSW}^{-1}$ (range: $0-3.45$ ind. gSW $^{-1}$; Fig. 3). The infestation intensity in River B on 22 May 2014 was $0.142 \pm 0.183$ ind. gSW ${ }^{-1}$ (0-0.361 ind. gSW ${ }^{-1}$; Fig. 3). 


\section{I. salmonis infestation prevalence and intensity in wild juveniles}

In River A, I. salmonis infestation prevalence was $100 \%$ in the upstream region (freshwater) as well as at the river mouth (brackish water; Table 1). In River B, infestation prevalence was $30 \%$ on 7 May 2014 and $0 \%$ on 22 May 2014 (Table 1). The infestation intensities on River A ranged from $6.72 \times 10^{5}$ to $4.97 \times$
$10^{7}$ rDNA copies $\mathrm{gSW}^{-1}$ in the upstream region $\left(3.05 \times 10^{7} \pm 1.86 \times 10^{7} \mathrm{rDNA}^{4}\right.$ copies $\left.\mathrm{gSW}^{-1}\right)$ and from $9.35 \times 10^{4}$ to $5.02 \times 10^{6} \mathrm{rDNA}$ copies $\mathrm{gSW}^{-1}$ at the river mouth $\left(2.34 \times 10^{6} \pm 2.56 \times 10^{6} \mathrm{rDNA}\right.$ copies $\mathrm{gSW}^{-1}$; Fig. 4). The infestation intensity of River B on 7 May 2014 ranged from 0 to $3.61 \times 10^{5}$ rDNA copies $\mathrm{gSW}^{-1}\left(1.46 \times 10^{5} \pm 3.49 \times 10^{5} \mathrm{rDNA}\right.$ copies $\mathrm{gSW}^{-1}$; Fig. 4).

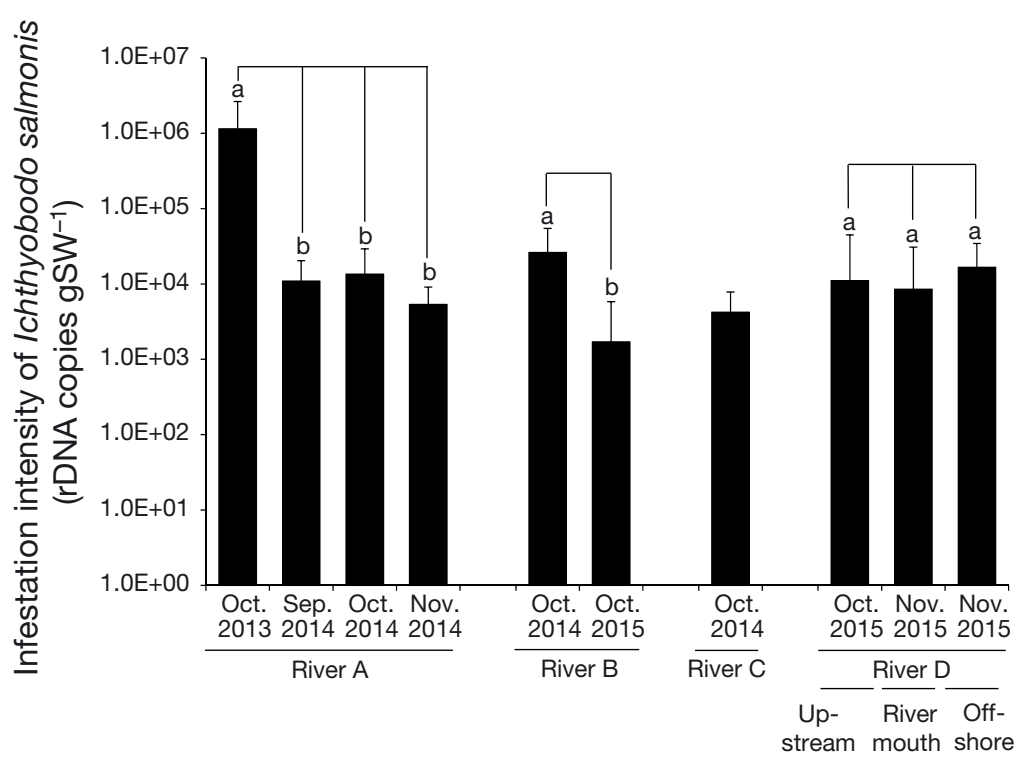

Fig. 2. Infestation intensity of Ichthyobodo salmonis in adult wild chum salmon Oncorhynchus keta. Data are expressed as means \pm SD $(n=5-10)$. Other details as in Fig. 1

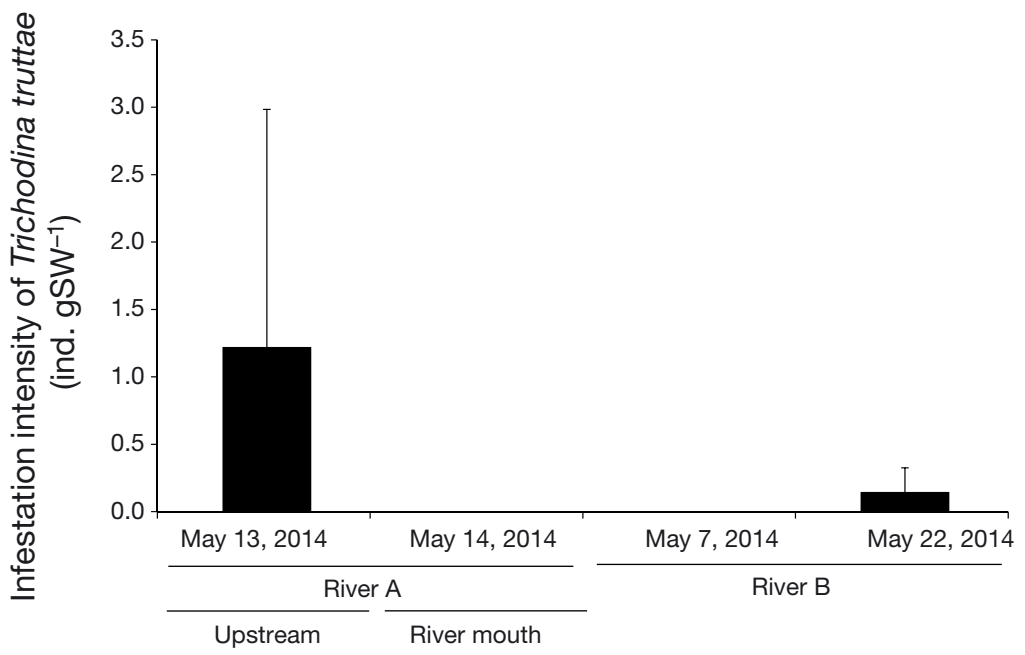

Fig. 3. Infestation intensity of Trichodina truttae in juvenile wild chum salmon Oncorhynchus keta. Data are expressed as means \pm SD $(\mathrm{n}=10)$. Data on 14 May in River A and on 22 May in River B showed no infestation of $T$. truttae

\section{Experimental transmission}

The initial infestation intensities of the 2 protozoans on fish used for the transmission experiment were $1.21 \pm 1.76$ ind. $\mathrm{gSW}^{-1}$ for T. truttae (Fig. 3), and $3.05 \times 10^{7} \pm 1.86 \times 10^{7}$ rDNA copies $\mathrm{gSW}^{-1}$ for I. salmonis (Fig. 4). The control group was not infested by $T$. truttae and I. salmonis for the whole time period of the transmission experiment. A Mann-Whitney $U$-test with the Bonferroni correction following a KruskalWallis test could detect changes in infestation intensity of the 2 protozoans during the transmission experiment, and single Mann-Whitney $U$-tests revealed differences in intensity between the control and the infested groups at each sampling time. From Day 7 to Day 63, the intensities of both parasites on fish in the tank initially designated the 'infested' group were significantly greater as compared to intensities on fish in the tank set as the control group ( $p<0.05$; Fig. 5). The intensity of $T$. truttae in the infested group increased $(\mathrm{p}<0.01)$ beginning on Day $7\left(7.14 \times 10^{-1} \pm 3.59 \times\right.$ $10^{-1}$ ind. $\left.\mathrm{gSW}^{-1}\right)$, reached a maximum on Day $35\left(4.29 \times 10^{3} \pm 1.54 \times 10^{3}\right.$ ind. $\left.\mathrm{gSW}^{-1}\right)$, and decreased $(\mathrm{p}<0.01)$ from Day 35 to Day $63\left(8.41 \pm 2.64\right.$ ind. gSW $^{-1}$; Fig. 5). The intensity of $I$. salmonis in the infested group increased $(p<0.01)$ from Day 0 (0 rDNA copies $\left.\mathrm{gSW}^{-1}\right)$ to Day 14 $\left(35.5 \pm 18.9\right.$ rDNA copies $\left.\mathrm{gSW}^{-1}\right)$, then showed no change $(\mathrm{p}>0.05)$ from Day 14 to Day $35(37.0 \pm 25.9$ rDNA copies $\left.\mathrm{gSW}^{-1}\right)$, but increased $(\mathrm{p}<0.01)$ again from Day 35 to Day $56\left(2.68 \times 10^{8} \pm 1.04\right.$ $\times 10^{8}$ rDNA copies $\mathrm{gSW}^{-1}$ ), and finally decreased $(\mathrm{p}<0.01)$ from Day 56 to Day $63\left(8.59 \times 10^{4} \pm 3.95 \times 10^{4}\right.$ rDNA copies 


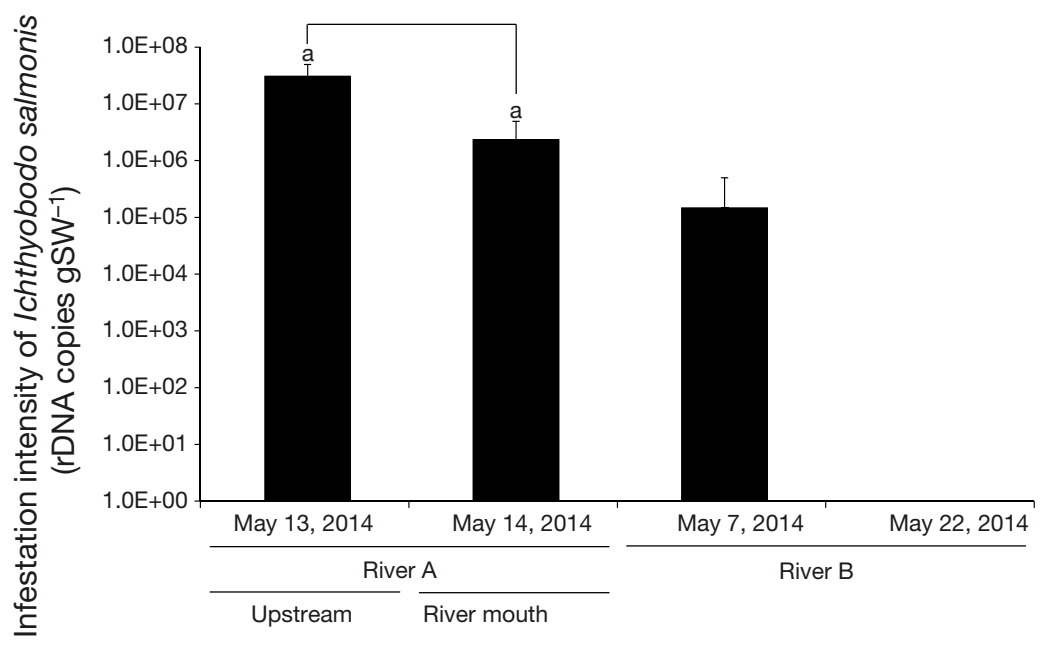

Fig. 4. Infestation intensity of Ichthyobodo salmonis in juvenile wild chum salmon Oncorhynchus keta. Data are expressed as means \pm SD $(n=10)$. Data on 22 May in River B showed no infestation of $I$. salmonis. The infestation intensities of $I$. salmonis were statistically compared between sampling times or between sampling points on each river with the original Mann-Whitney $U$-test. Same superscript letters on the data columns indicate no significant differences $(p>0.05)$

gSW $^{-1}$; Fig. 5). Weekly cumulative mortality in the infested group increased between Day $21(0.666 \%)$ and Day $63(81.5 \%)$, whereas the control group showed no change in mortality rate $(0 \%)$ during the course of the experiment.

\section{DISCUSSION}

\section{Infestation status of Trichodina truttae in wild chum salmon}

Previous studies have suggested that $T$. truttae is strictly a freshwater species. For instance, T. truttae infestations could be controlled by bathing freshwater-adapted Atlantic salmon Salmo salar in seawater (Khan 1991), and infestations have been observed only on freshwater-adapted salmonids (Arthur \& Margolis 1984, Khan 1991, Urawa 1992b, Ferguson et al. 2011, Mizuno et al. 2016). Our study confirmed T. truttae infestation on both adult and juvenile wild chum salmon in freshwater only, even though chum salmon are diadromous (Salo 1991). This finding strongly suggests that $T$. truttae completes its life cycle only in freshwater and that adult chum salmon are infested with the parasite after entry into rivers. Furthermore, among studies of anadromous Pacific salmonids, ours is the first to report $T$. truttae infestation of returning wild adults during their upstream migration.
The infestation prevalence and intensity of a variety of freshwateradapted Trichodina spp. are affected by several environmental factors, such as changes in temperature (Nilsen 1995, Schisler et al. 1999, Kristmundsson et al. 2006, Yemmen et al. 2010, 2011), water flow (Schisler et al. 1999), water quality (Nnadi et al. 2011), fish population density (Kristmundsson et al. 2006), and seasonality (Özer 2000, 2003, Balta et al. 2008, Özer et al. 2015). Any of these factors may have caused time- or location-dependent variations in the infestation prevalence or intensity of $T$. truttae on the freshwater-adapted adult and juvenile wild chum salmon in the present study. In addition, ecological factors during the upstream migration of adult salmon possibly affected infestation with the parasites. As mentioned, T. truttae may infest adult salmon after they enter their natal river. Early-run adults remain in rivers for longer than late-run adults (Salo 1991), which may explain why the infestation prevalence of T. truttae on the captured adults from River A in 2014 steadily decreased between September and November. The maximum mean infestation intensity of $T$. truttae on wild juveniles (1.21 ind. $\mathrm{gSW}^{-1}$ ) was much less than the lowest intensity (approximately 700-1500 ind. gSW $^{-1}$ ) shown to cause mortality in hatchery-reared chum salmon juveniles (Urawa 1992b, Mizuno et al. 2016).

\section{Infestation status of Ichthyobodo salmonis in wild chum salmon}

As adults, Japanese chum salmon travel long distances in the North Pacific, Okhotsk Sea, or Bering Sea for several years before returning to their natal river for spawning (Urawa 2000). A previous infestation experiment showed that I. salmonis on hatcheryreared chum salmon juveniles reproduced in both freshwater and seawater (Urawa \& Kusakari 1990). Subsequent observations confirmed that juveniles could become infested with I. salmonis as they migrated downstream in rivers, and that the parasite persisted on juveniles in coastal waters (Urawa 1996). Notably, the present study found I. salmonis infestations on chum salmon adults sampled from coastal waters just before they entered rivers, as well 


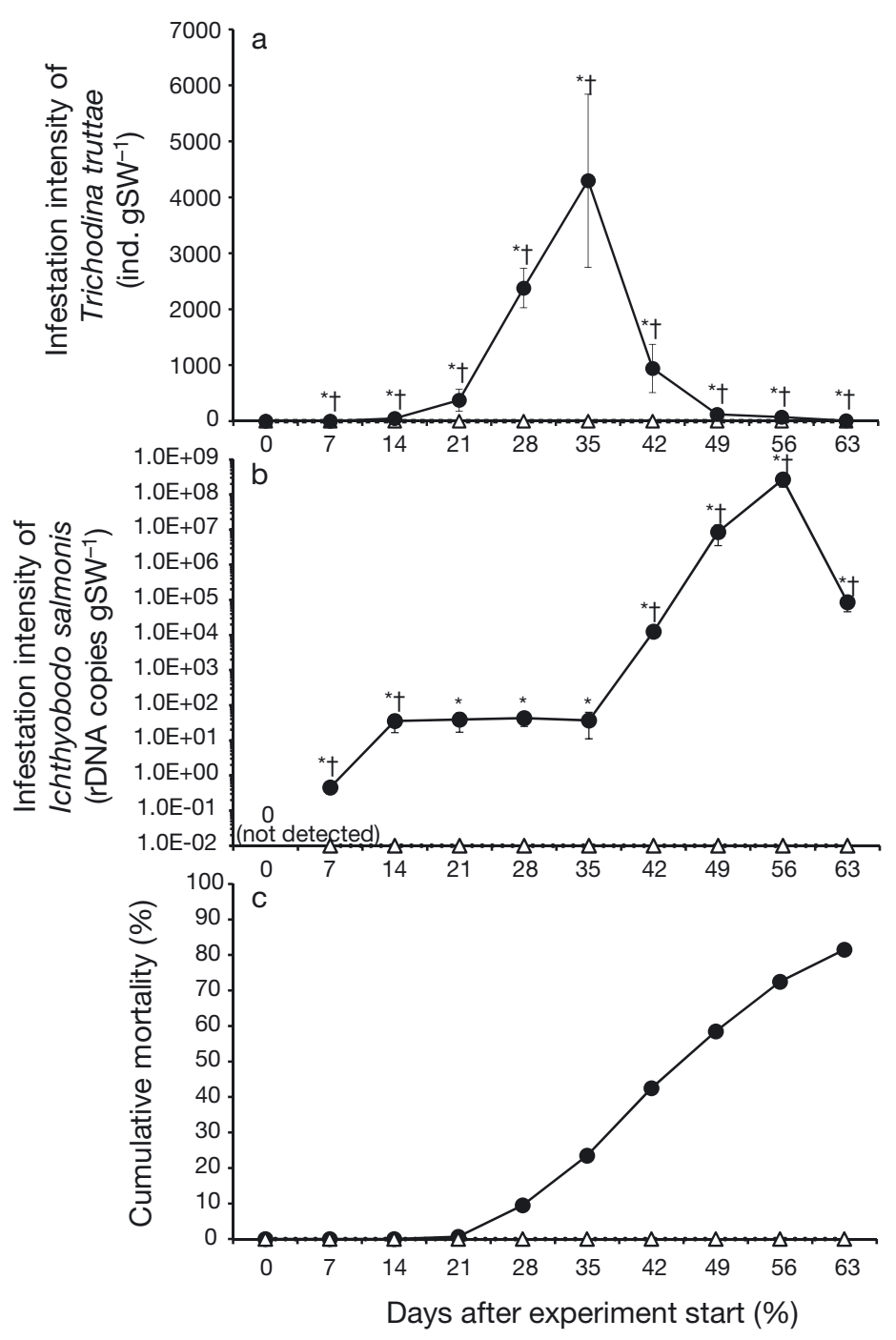

Fig. 5. Changes in infestation intensities of (a) Trichodina truttae, as individuals per gram wet sample weight (ind. $\mathrm{gSW}^{-1}$ ), (b) Ichthyobodo salmonis, as rDNA copies $\mathrm{gSW}^{-1}$, and (c) weekly cumulative mortality during the transmission experiment (from wild chum salmon juveniles Oncorhynchus keta to hatchery-reared juveniles). Triangles and circles represent the control and the 'infested' groups, respectively. All data on parasite intensity are shown as means $\pm \mathrm{SD}$ $(n=10)$. Statistical comparisons of parasite intensities between the control and infested groups at each experimental time and between 2 different times in each of the control and infested groups were performed with the original Mann-Whitney $U$-test. Asterisks $\left({ }^{*}\right)$ mark significant differences $(\mathrm{p}<0.05)$ when making comparisons with the control group for each experiment time. Crosses $(\mathrm{I})$ indicate significant differences $(\mathrm{p}<0.05)$ when making comparisons to data $7 \mathrm{~d}$ previously in each of the control and infested groups

as during their upstream river migration. These findings demonstrate that $I$. salmonis is able to infest chum salmon at different developmental stages, in both river and ocean habitats. Most importantly, to our knowledge, this is the first report of I. salmonis infestation in adults of an anadromous Pacific salmonid on an upstream migration.

Several primary factors, such as increased water temperature (Schisler et al. 1999, Isaksen et al. 2010), cohabitation with other infested fish (Isaksen et al. 2010), high fish densities (Urawa 1995), low water flow (Urawa 1995, Schisler et al. 1999), and the presence of (periodic acid-Schiff-positive) epidermal mucous cells (Urawa 1992a), can influence variations in infestation prevalence and intensity of a variety of freshwater-adapted Ichthyobodo spp. In the present study, time- and locationdependent variations in I. salmonis infestation of the freshwater-adapted wild adult and juvenile chum salmon were likely affected by any of these unrecorded factors. The maximum infestation intensity of $I$. salmonis on wild chum salmon juveniles $\left(3.05 \times 10^{7}\right.$ rDNA copies $\mathrm{gSW}^{-1}$ ) was estimated as $1.62 \times 10^{3}$ cells of $I$. salmonis $\mathrm{gSW}^{-1}$, using a regression formula between individual numbers of I. salmonis and their rDNA copy numbers (cf. Mizuno et al. 2017). The infestation intensity on wild juveniles in this study was lower than the intensity $\left(1.0 \times 10^{4}\right.$ cells gSW $\left.{ }^{-1}\right)$ found to cause mortality in hatchery-reared juveniles (Urawa 1996).

\section{Wild chum salmon as an infestation source of T. truttae and I. salmonis}

Previous infestation transmission experiments suggested that $T$. truttae and I. salmonis would be only separately established in stocks of hatchery-reared chum salmon juveniles (Urawa 1992a,b). Our transmission experiment notably found that both parasites could be transferred at the same time from wild to hatchery-reared juveniles, through untreated culture water, thereby causing high mortalities in the hatchery fish. In the past, salmon hatcheries that have utilized water from Rivers A, B, C, and D have recorded outbreaks of trichodinosis and ichthyobodosis (Urawa 1992c). These findings demonstrate that wild chum salmon juveniles can be a source of $T$. truttae and I. salmonis infestations in hatcheries. Mixed transmission of $T$. truttae and $I$. salmonis was characterized by increased intensity of $T$. truttae followed by that of I. salmonis, with continuously increased mortality to more than $80 \%$ among the host fish during the experiment. This observation pos- 
sibly shows that enhancement of $T$. truttae and $I$. salmonis infestations collectively affects the increasing juvenile mortality in the transmission experiment. Previously, experimental transmission between hatcheryreared juveniles showed that the proliferative speed to maximum intensity was $2-3$ wk faster for $T$. truttae than for I. salmonis, with less than $60 \%$ mortality among the host fish (Urawa 1992a,b, Mizuno et al. 2016). Environmental stress induced by overcrowding and/or an inadequate water supply further increased host mortality to $90 \%$ in experimental transmission of I. salmonis to chum salmon juveniles (Urawa 1995). Hence, differing proliferative capabilities possibly exist in the 2 parasite species. In addition, variation in the degree of host mortality may result not only from mixed infestations (by T. truttae or I. salmonis) but may also arise as a consequence of an unfavorable environment. The present experiment recorded the maximum transmission intensity for each parasite as occurring 1-2 wk later than that recorded in previous experiments; however, this difference could have been caused by differences in fish size and origin, the biological defenses of the host, the initial intensity of the 2 parasites on the fish, the infestation source, and unknown impacts of mixed transmission of $T$. truttae and I. salmonis.

\section{Infestation route of $T$. truttae and $I$. salmonis in salmon hatcheries}

The assumed infestation route of $T$. truttae and I. salmonis into salmon hatcheries is depicted in Fig. 6. T. truttae infests a variety of instream wild salmonids, including chum salmon adults (Mizuno et al. 2016) and juveniles (present study). As the ciliate separates from the body surface of wild fish, it may intrude into hatchery ponds via river water, and is therefore capable of infesting hatchery-reared chum salmon juveniles. Thus, the infestation cycle of T. truttae is completed only in freshwater environments. In contrast, the external flagellate I. salmonis may infest wild chum salmon throughout their life cycle, in both rivers and at sea; separated from the wild salmon, the parasite may invade hatcheries via untreated river water. Furthermore, intrusions of both T. truttae and I. salmonis into hatcheries can occur through adult stocks maintained in hatchery ponds and via the work of artificial fertilization. Likewise, moving juveniles between ponds in a hatchery or between 2 different hatcheries may assist the transmission of $T$. truttae or I. salmonis. Stocking of hatchery-reared juveniles infested with 2 protozoans and unsterilized hatchery effluent water may affect

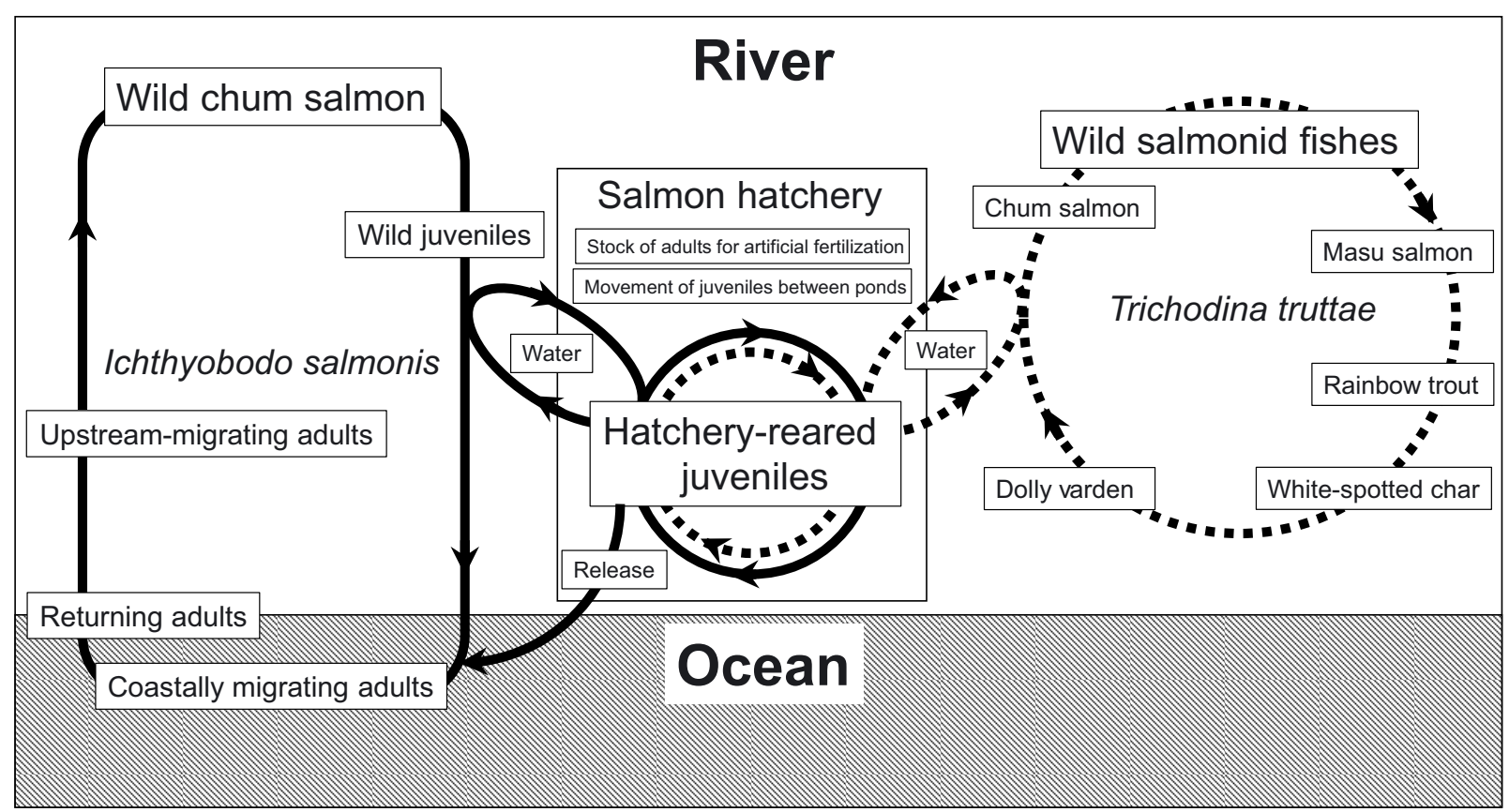

Fig. 6. Expected infestation routes of 2 ectoparasites, Trichodina truttae and Ichthyobodo salmonis, in a salmon hatchery. Arrows with a broken or solid line indicate the presumed infestation routes of $T$. truttae and $I$. salmonis, respectively. The lifecycle of $T$. truttae infestation in a variety of wild salmonids is completed only in freshwater, whereas I. salmonis infection of chum salmon Oncorhynchus keta occurs in both freshwater and seawater. Utilization of untreated river water and/or contamination of ponds by stock of adult chum salmon for artificial fertilization and by movement of juveniles between ponds cause outbreak of the 2 protozoan diseases 
infestation status of wild salmonid fishes. Our results and those of Mizuno et al. (2016) suggest subclinical infestation of $T$. truttae and I. salmonis on wild salmonid fishes in northern Japan, but we did not detect heavy infection to cause protozoan diseases in wild salmonid fishes. Accordingly, outbreaks of trichodinosis and ichthyobodosis at hatcheries possibly contribute to maintain the cycle and to spread infestations of T. truttae and I. salmonis.

In conclusion, we have presented new information on the infestation status of T. truttae and I. salmonis in wild chum salmon at different developmental stages, inhabiting rivers of northern Japan. Our findings point to wild chum salmon as a potential infestation source of these 2 ectoparasites, thereby establishing an assumed infestation route into hatcheries. It may be vital to decrease the overall parasite prevalence in chum salmon populations to prevent ultimate transmission of the parasites to hatchery-reared fish. Unfortunately, I. salmonis may remain embedded in hatcheries to some extent, since Ichthyobodo spp. probably produce permanent cysts that allow long-term survival (Bauer 1959, Robertson 1985). Accordingly, referring to the assumed infestation routes described here, hatchery programs should establish procedures to terminate the intrusion of these 2 parasites into hatcheries, such as methods to disinfect hatchery ponds or the river water supplied for fish culture.

Acknowledgements. We are grateful to staff at the Hokkaido Salmon Propagation Association and at the Salmon and Freshwater Fisheries Research Institute of the Hokkaido Research Organization for help with collecting the fish. This study was supported by JSPS KAKENHI Grant Number 15K07564.

\section{LITERATURE CITED}

Arthur JR, Margolis L (1984) Trichodina truttae Mueller, 1937 (Ciliophora: Peritrichida), a common pathogenic ectoparasite of cultured juvenile salmonid fishes in British Columbia: redescription and examination by scanning electron microscopy. Can J Zool 62:1842-1848

Balta F, Kayis S, Altinok I (2008) External protozoan parasites in three trout species in the eastern Black Sea region of the Turkey: intensity, seasonality, and their treatments. Bull Eur Assoc Fish Pathol 28:157-162

Bauer ON (1959) Parasites of freshwater fish and the biological basis for their control. Bull State Sci Res Inst Lake River Fish 49:15-18

Callahan HA, Noga EJ (2002) Tricaine dramatically reduces the ability to diagnose protozoan ectoparasite (Ichthyobodo necator) infections. J Fish Dis 25:433-437

Ferguson JA, St-Hilaire S, Peterson TS, Rodnick KJ, Kent ML (2011) Survey of parasites in threatened stocks of coho salmon (Oncorhynchus kisutch) in Oregon by exam- ination of wet tissues and histology. J Parasitol 97: 1085-1098

* Isaksen TE, Karlsbakk EG, Sundnes A, Nylund A (2010) Patterns of Ichthyobodo necator sensu stricto infections on hatchery-reared Atlantic salmon Salmo salar in Norway. Dis Aquat Org 88:207-214

* Khan RA (1991) Mortality in Atlantic salmon (Salmo salar) associated with trichodinid ciliates. J Wildl Dis 27: 153-155

Kobayashi T (1980) Salmon propagation in Japan. In: Thorpe JE (ed) Salmon ranching. Academic Press, London, p 91-107

Kristmundsson Á, Eydal M, Helgason S (2006) Progress of co-infections of Trichodina cooperi and T. murmanica parasitising farmed Atlantic cod Gadus morhua juveniles in Iceland. Dis Aquat Org 71:213-223

* Mizuno S, Urawa S, Miyamoto M, Hatakeyama M and others (2016) The epidemiology of the trichodinid ciliate Trichodina truttae on hatchery-reared and wild salmonid fish in Hokkaido. Fish Pathol 51:199-209

* Mizuno S, Urawa S, Miyamoto M, Hatakeyama M, Koide N, Ueda H (2017) Quantitative analysis of Ichthyobodo salmonis, an ectoparasitic flagellate infecting juvenile chum salmon Oncorhynchus keta in hatcheries. Fish Sci 83: 283-290

Nilsen F (1995) Description of Trichodina hippoglossi n. sp. from farmed Atlantic halibut larvae Hippoglossus hippoglossus. Dis Aquat Org 21:209-214

Nnadi EI, Awi-Waadu GDB, Imafidor HO (2011) Association between parasitic infection and fish habitat. J Res Natl Dev 9:186-190

Özer A (2000) The occurrence of three species of Trichodina (Ciliophora: Peritrichida) on Cyprinus carpio in relation to culture conditions, seasonality and host characteristics. Acta Protozool 39:61-66

Özer A (2003) The occurrence of Trichodina domerguei Wallengren, 1987 and Trichodina tenuidens Fauré-Fremiet, 1944 (Peritrichia) on three-spined stickleback, Gasterosteus aculeatus L., 1758 found in a brackish and freshwater environment. Acta Protozool 42:41-46

Özer A, Öztürk T, Kornyychuk YM, Yurakhno V (2015) Trichodina gobii (Ciliophora: Trichodinidae) on whiting Merlangius merlangus with a checklist from Turkish and Russian coasts of the Black Sea. Acta Zool Hung 62: 119-134

Robertson DA (1985) A review of Ichthyobodo necator (Henneguy, 1983) an important and damaging fish parasite. In: Muir JF, Roberts RJ (eds) Recent advances in aquaculture. Croom Helm, London, p 1-30

Salo EO (1991) Life history of chum salmon. In: Groot C, Margolis L (eds) Pacific salmon life histories. UBC Press, Vancouver, BC, p 233-309

* Schisler GJ, Walker PG, Chittum LA (1999) Gill ectoparasites of juvenile rainbow trout and brown trout in the upper Colorado River. J Aquat Anim Health 11:170-174

*Urawa S (1992a) Epidermal responses of chum salmon (Oncorhynchus keta) fry to the ectoparasitic flagellate Ichthyobodo necator. Can J Zool 70:1567-1575

* Urawa S (1992b) Trichodina truttae Mueller, 1937 (Ciliophora: Peritrichida) on juvenile chum salmon (Oncorhynchus keta): pathogenicity and host-parasite interactions. Fish Pathol 27:29-37

Urawa S (1992c) Host range and geographical distribution of the ectoparasitic protozoans, Ichthyobodo necator, Trichodina truttae and Chilodonella piscicola on hatchery- 
reared salmonids in northern Japan. Sci Rep Hokkaido Salmon Hatch 46:175-203

Urawa S (1993) Effects of Ichthyobodo necator infections on seawater survival of juvenile chum salmon (Oncorhynchus keta). Aquaculture 110:101-110

Urawa S (1995) Effects of rearing conditions on growth and mortality of juvenile chum salmon (Oncorhynchus keta) infected with Ichthyobodo necator. Can J Fish Aquat Sci $52: 18-23$

Urawa S (1996) The pathobiology of ectoparasitic protozoans on hatchery-reared Pacific salmon. Sci Rep Hokkaido Salmon Hatch 50:1-99

Urawa S (2000) Ocean migration route of Japanese chum salmon with a reference to future salmon research. Natl Salmon Resour Cent Newsl 5:3-9

Urawa S (2013) Control of the parasitic flagellate Ichthyobodo salmonis, causative agent of marine mortalities of juvenile chum salmon. North Pac Anadromous Fish Comm Tech Rep 9:214-215

Urawa S, Arthur JR (1991) First record of the parasitic ciliate Trichodina truttae Mueller, 1937 on chum salmon fry

Editorial responsibility: Lori Gustafson,

Fort Collins, Colorado, USA
(Oncorhynchus keta) from Japan. Fish Pathol 26:83-89

* Urawa S, Kusakari M (1990) The survivability of the ectoparasitic flagellate Ichthyobodo necator on chum salmon fry (Oncorhynchus keta) in seawater and comparison to Ichthyobodo sp. on Japanese flounder (Paralichthys olivaceus). J Parasitol 76:33-40

Urawa S, Freeman M, Mizuno S (2014) Taxonomic status of Ichthyobodo spp., ectoparasitic flagellates causing high mortality of Pacific salmon. In: ISAAH Organization and Program Committees (eds) Proc 7th Int Symp Aquat Anim Health. Fish Health Section, American Fisheries Society, Portland, OR, p 275

Yemmen C, Quilichini Y, Ktari MH, Marchand B, Bahri S (2010) Morphological, ecological and histopathological studies of Trichodina gobii Raabe, 1959 (Ciliophora: Peritrichida) infecting the gills of Solea aegyptiaca. Parasitology 6:258-263

Yemmen C, Ktari MH, Bahri S (2011) Seasonality and histopathology of Trichodina puytoraci Lom, 1962, a parasite of flathead mullet (Mugil cephalus) from Tunisia. Acta Adriat 52:15-20

Submitted: May 8, 2017; Accepted: July 27, 2017

Proofs received from author(s): October 6, 2017 